\title{
Cancer and Non-Cancer Controls in Studies on the Effect of Tobacco and Alcohol Consumption
}

\author{
SALVATORE BARRA*, ANNA E BARÓN***, SILVIA FRANCESCHI*, $\dagger$, RENATO TALAMINI* AND \\ CARLO LA VECCHIA,$\S$
}

Barra S (Epidemiology Unit, Aviano Cancer Center, Via Pedemontana Occ, 33081 Aviano (PN), Italy), Barón A E, Franceschi S, Talamini R and La Vecchia C. Cancer and non-cancer controls in studies on the effect of tobacco and alcohol consumption. International Journal of Epidemiology 1991; 20: 845-851.

A comparison of risk estimates using controls with other cancers versus controls with acute diseases unrelated to tobacco and alcohol consumption in the study of the effect of these two factors has been performed using data on tumours of the oral cavity and pharynx from an ongoing case-control surveillance programme in Northeastern Italy. Similar results were obtained using either type of controls: as compared to never smokers, moderate smokers $(\leqslant 14$ cigarettes/day) showed age- and sex-adjusted odds ratio (OR) $=5.2(95 \%$ confidence interval (CI): $2.9-9.2)$ when using cancer controls and 5.8 (95\% Cl: 3.3-10.1) when using non-cancer controls. Similarly, those who had smoked for 40 years or longer showed ORs of 7.4 (95\% Cl: 4.0-13.6) and 8.8 (95\% Cl: $4.9-15.6)$, respectively, using cancer and noncancer controls. For moderate drinkers of alcoholic beverages (21-34 drinks/week) and heavy drinkers ( $\geqslant 84$ drinks/ week) the ORs, as compared to individuals who drank<21 drinks/week, were $1.9(95 \% \mathrm{Cl}: 1.0-3.6)$ and 2.2 (95\% Cl: $1.2-$ $4.0)$ and 10.6 (95\% Cl: 5.5-20.6) and $11.4(95 \% \mathrm{Cl}: 6.0-21.4)$ using cancer and non-cancer controls, respectively. The same comparability of ORs for tobacco- and alcohol-related variables using either type of controls was observed when separate analyses of the two sexes were performed. The close similarity between cancer and non-cancer controls in studies on tabacco- and alcohol-related risks may be exploited when the choice of other types of controls would increase the costs and the feasibility of the study, and thus hamper its statistical power. Moreover, this investigation provides some reassurance about the validity of risk estimates using carefully selected groups of hospital controls.

Tobacco and alcohol have been well established as the most important risk factors for tumours of the upper aero-digestive tract. ${ }^{1.2}$ The influence of these habits has been explored in several studies ${ }^{1-11}$ using either community or hospital controls. In a few studies, ${ }^{12-15}$ a cancer control group has been used and in one study ${ }^{16}$ results obtained with multiple control groups including cancer and non-cancer hospital controls have been shown.

The advantages of the use of cancer controls, which

\footnotetext{
*Epidemiology Unit, Aviano Cancer Center, Via Pedemontana Occ., 33081 Aviano (PN), Italy.

- Department of Preventive Medicine and Biometrics, University of Colorado Health Sciences Center, Denver, CO 80262, USA.

†Epidemiology and Cancer Working Group, European Cancer Prevention Organization (ECP), Bruxelles, Belgium;

‡'Mario Negri' Institute for Pharmacological Research, Via Eritrea 62, 20157 Milan, Italy.

§Institute of Social and Preventive Medicine, University of Lausanne, 1005 Lausanne, Switzerland.
}

have been discussed by some authors, ${ }^{17,18}$ include the reduction of selection, recall and interviewer biases. However a potential disadvantage of their use is the inclusion of cancer types which are associated, positively or negatively, with the exposures of interest, resulting in under- or overestimation of risk estimates.

The purpose of the present investigation is to examine the comparability of risk estimates for smoking and drinking habits in tumours of the oral cavity and pharynx using two different control groups, one selected from patients admitted to hospital for a wide spectrum of acute diseases unrelated to tobacco and alcohol use, and the other control group selected from patients with cancers also believed to be unrelated to these exposures. The results are expected to be useful in demonstrating that cancer controls constitute an appropriate control group in this context. More importantly, they will provide further information about the validity of risk estimates using hospital controls for two behavioural risk factors which have been shown to be less than reliably, and therefore inaccurately, reported in 
hospital interview settings. ${ }^{19}$ For this purpose we took advantage of the data collected in the framework of a case-control surveillance programme ongoing since 1985 in Pordenone province, Northeastern Italy.

\section{MATERIALS AND METHODS}

The study design of the present case-control surveillance has been described elsewhere.$^{20}$ Briefly, 236 male cases and 36 female cases below age 75 years (median age $=60$ ), with histologically-confirmed cancer of the oral cavity and pharynx, diagnosed in the hospitals of the western part of the Friuli-Venezia Giulia region (Pordenone province) between January 1985 and July 1990 , constituted the case group. All cases were resident in the same area in which the hospitals are located.

Similarly, criteria for inclusion as a cancer control were: (1) to be below age 75 years (median age $=57$ ) (2) to be affected by a cancer type not consistently related to tobacco or alcohol consumption and (3) to come from the same catchment area as the cases of cancer of the oral cavity and pharynx. After a review of recent epidemiological literature and our partly published case-control study results ${ }^{21-23}$ five tumour sites were selected for inclusion as controls: colorectal, renal cell, prostate, thyroid, and haematological (i.e., Hodgkin's disease, non-Hodgkin's lymphoma and multiple myeloma). All eligible cancer controls were included, thus making a group in which each cancer site accounted for about one-fifth of the total. Table 1 shows the distribution of 577 males and 446 females according to these cancer sites.

Eligible non-cancer controls were individuals admitted for acute illnesses to selected departments of local hospitals. These departments were chosen in order to cover the same catchment area as those from where cancer patients originated and to allow the inclusion of a wide spectrum of diseases (i.e., no category was to account for more than a quarter of the total). Specifically excluded were patients who had malignant tumours or any condition consistently related to alcohol or tobacco consumption. A total of 1122 male controls and 762 female controls chosen on the basis of age (below 75 years, median age $=58$ ), and area of residence were interviewed. Their distribution according to hospital discharge diagnostic categories is given in Table 1. In particular, non-traumatic orthopaedic conditions included mainly low back pain and disk disorders; traumatic conditions included mainly sprains and fractures; and surgical conditions were chiefly represented by benign cysts, abdominal hernia and acute appendicitis. The 'Others' category mostly included skin illnesses.
All study patients were interviewed in hospital. Refusals were about $3 \%$ for all three study groups. Interviewers were pilot-trained to reduce variability using the same pre-coded questionnaire to obtain information on sociodemographic factors, occupation, lifestyle, including tobacco and alcohol consumption habits, dietary habits, and past history of selected medical conditions. All of the information referred to the patient's situation before the onset of the disease which led to the hospital admission.

Information on smoking habits included smoking status (never, ex, current smoker), the type of products smoked (cigarettes, pipe or cigar), the number of cigarettes (or pipe/cigars) smoked per day before the onset of the disease, duration of cigarette smoking, the age at starting smoking, and, for ex-smokers, years since they quit smoking. In the part of the questionnaire dealing with alcohol consumption, the number of glasses of alcohol-containing beverages (wine, beer, spirits) consumed per week was elicited. Taking into account the different alcohol concentration, consumption of one drink corresponded to $150 \mathrm{ml}$ of wine, $330 \mathrm{ml}$ of beer and $30 \mathrm{ml}$ of spirits (i.e. approximately $15 \mathrm{ml}$ of ethanol).

The odds ratios (ORs), together with their 95\% approximate confidence interval $(\mathrm{CI})$ were computed accounting simultaneously for age (in quinquennia), sex, years of education, occupation and for the reciprocal confounding effects of tobacco and alcohol. Unconditional multiple logistic regression with maximum likelihood estimation was used to obtain these estimates. ${ }^{24}$

\section{RESULTS}

Table 2 shows the distribution of cases and two control groups according to sex and sociodemographic characteristics. When compared to either cancer or noncancer controls, cases of cancer of the oral cavity and pharynx appeared to be less educated. Also the distribution by occupation was different and, in particular, farmers were more frequent among male cases than among either of the control groups (27\% versus $18 \%$ of cancer controls and $14 \%$ of non-cancer controls), while fewer female cases than controls reported clerical/professional occupation ( $6 \%$ versus $20 \%$ in both control groups).

Table 3 gives the risks of cancer of the oral cavity and pharynx for various measures of tobacco consumption. A close similarity in the ORs using the two different types of controls was evident for all smoking-related variables. Moderate smokers ( $\leqslant 14$ cigarettes/day) showed, as compared to never smokers, an OR of 5.2 (95\% CI: 2.9-9.2) when contrasted to cancer controls 
TABLE I Distribution of cancer and non-cancer controls according to sex and diagnosis. Pordenone, Italy, 1985-1990

\begin{tabular}{|c|c|c|c|c|c|}
\hline \multicolumn{3}{|c|}{$\begin{array}{c}\text { Cancer controls } \\
(\mathrm{No} .=577)\end{array}$} & \multicolumn{3}{|c|}{$\begin{array}{l}\text { Non-cancer controls } \\
(\mathrm{No} .=1122)\end{array}$} \\
\hline & No. & $(\%)$ & & No. & $(\%)$ \\
\hline \multicolumn{6}{|l|}{ Males } \\
\hline Colorectal cancer & 130 & (22) & Orthopaedic & 251 & (22) \\
\hline Kidney cancer & 82 & (14) & Trauma & 291 & (26) \\
\hline Prostate cancer & 125 & $(22)$ & Surgical conditions & 303 & (27) \\
\hline Haematological cancer & 195 & (34) & Eye disorders & 67 & (6) \\
\hline Thyroid cancer & 45 & (8) & Others & 210 & (19) \\
\hline \multicolumn{3}{|c|}{$\begin{array}{c}\text { Cancer controls } \\
(\text { No. }=446)\end{array}$} & \multicolumn{3}{|c|}{$\begin{array}{l}\text { Non-cancer controls } \\
(\text { No. }=762)\end{array}$} \\
\hline & No. & $(\%)$ & & No. & $(\%)$ \\
\hline \multicolumn{6}{|l|}{ Females } \\
\hline Colorectal cancer & 82 & (18) & Orthopaedic & 243 & (32) \\
\hline Kidney cancer & 51 & (11) & Trauma & 151 & (20) \\
\hline Haematological cancer & 173 & (39) & Surgical conditions & 131 & (17) \\
\hline \multirow[t]{2}{*}{ Thyroid cancer } & 140 & (31) & Eye disorders & 53 & (7) \\
\hline & & & Others & 183 & (24) \\
\hline
\end{tabular}

and $5.8(95 \% \mathrm{CI}: 3.3-10.1)$ when contrasted to noncancer controls; the ORs associated with heavy smoking ( $\leqslant 25$ cigarettes/day) were 9.6 ( $95 \%$ CI: $4.9-18.9)$ and 12.2 (95\% CI: 6.4-23.2), respectively. Those who had smoked for 40 years or more had a 7.4-fold increased risk when compared to cancer controls and 8.8-fold increased risk when compared to non-cancer controls. Such similarities in the ORs were also obtained with age at starting smoking $(\mathrm{OR}=6.8,95 \%$ $\mathrm{CI}: 3.8-12.2$, and $6.6,95 \% \mathrm{CI}: 3.8-11.5$, using cancer and non-cancer controls, respectively, for $\leqslant 16$ versus $\geqslant 25$ years) and, among ex-smokers, with years since quitting $(\mathrm{OR}=3.9$ using both types of controls for $<10$ years).

Drinking-related variables are shown in Table 4. For moderate wine drinkers (21-34 drinks/week) the ORs, as compared to individuals who drank $<21$ drinks/ week, were 1.8 (95\% CI: $1.0-3.1)$ and 1.7 (95\% CI: 1.0-3.1) using cancer and non-cancer controls respectively. Heavy wine drinkers ( $\geqslant 84$ drinks/week) had

TABLE 2 Distribution of cases of cancer of the oral cavity and pharynx, and cancer and non-cancer controls according to sex and various sociodemographic characteristics. * Pordenone, Italy, 1985-1990

\begin{tabular}{|c|c|c|c|c|c|c|c|c|c|c|c|c|}
\hline & \multicolumn{4}{|c|}{$\begin{array}{l}\text { Oral cavity-pharynx } \\
\text { cancer cases }\end{array}$} & \multicolumn{4}{|c|}{ Cancer controls } & \multicolumn{4}{|c|}{ Non-cancer controls } \\
\hline & \multicolumn{2}{|c|}{ Males } & \multicolumn{2}{|c|}{ Females } & \multicolumn{2}{|c|}{ Males } & \multicolumn{2}{|c|}{ Females } & \multicolumn{2}{|c|}{ Males } & \multicolumn{2}{|c|}{ Females } \\
\hline & No. & $(\%)$ & No. & $(\%)$ & No. & $(\%)$ & No. & $(\%)$ & No. & $(\%)$ & No. & $(\%)$ \\
\hline \multicolumn{13}{|l|}{ Age (years) } \\
\hline$\leqslant 49$ & 58 & (25) & 7 & (19) & 126 & (22) & 164 & (37) & 353 & (32) & 313 & (41) \\
\hline $50-59$ & 65 & (28) & 15 & $(42)$ & 132 & (23) & 110 & $(25)$ & 331 & (29) & 177 & (23) \\
\hline $60-69$ & 85 & (36) & 11 & (31) & 168 & (29) & 95 & (21) & 283 & (25) & 152 & (20) \\
\hline$\geqslant 70$ & 28 & (12) & 3 & (8) & 151 & (26) & 77 & (17) & 155 & (14) & 120 & (16) \\
\hline \multicolumn{13}{|l|}{ Education (years) ${ }^{* *}$} \\
\hline$\leqslant 4$ & 58 & (25) & 15 & $(42)$ & 145 & $(25)$ & 142 & $(32)$ & 221 & (20) & 241 & (32) \\
\hline $5-7$ & 132 & (56) & 16 & (44) & 259 & (45) & 178 & $(40)$ & 540 & (48) & 333 & (44) \\
\hline$\geqslant 8$ & 45 & (19) & 5 & (14) & 173 & (30) & 126 & (28) & 361 & (32) & 187 & (24) \\
\hline \multicolumn{13}{|l|}{ Marital status } \\
\hline Never married & 34 & (14) & 2 & (6) & 61 & (11) & 62 & (14) & 133 & (12) & 102 & (13) \\
\hline Ever married & 202 & (86) & 34 & (94) & 516 & (89) & 384 & $(86)$ & 989 & (88) & 660 & (87) \\
\hline \multicolumn{13}{|l|}{ Occupation** } \\
\hline Clerical/Professional & 52 & (22) & 2 & (6) & 190 & (33) & 90 & $(20)$ & 346 & (31) & 149 & (20) \\
\hline Manual worker & 118 & $(50)$ & 10 & (27) & 266 & (46) & 108 & (24) & 609 & $(54)$ & 221 & (29) \\
\hline Farmer & 64 & (27) & 4 & (11) & 104 & (18) & 74 & (17) & 158 & (14) & 109 & (14) \\
\hline Other & 2 & (1) & 20 & (56) & 17 & (3) & 174 & (39) & 9 & (1) & 282 & (37) \\
\hline
\end{tabular}

* Total sample size varies because of missing values.

** Difference between cases and either control group was statistically significant $(P<0.01)$. 
TABLE 3 Odds ratios for cancer of the oral cavity and pharynx according to smoking habits. Pordenone, laly, 1985-1990

\begin{tabular}{|c|c|c|c|c|c|c|c|c|}
\hline & \multicolumn{2}{|c|}{$\begin{array}{l}\text { Oral cavity pharynx } \\
\text { cancer cases }\end{array}$} & \multicolumn{2}{|c|}{ Cancer controls } & \multirow[t]{2}{*}{$\begin{array}{l}\text { Odds ratio** } \\
(95 \% \mathrm{CI})\end{array}$} & \multicolumn{2}{|c|}{$\begin{array}{l}\text { Non-cancer } \\
\text { controls }\end{array}$} & \multirow[t]{2}{*}{$\begin{array}{l}\text { Odds ratio** } \\
(95 \% \mathrm{CI})\end{array}$} \\
\hline & Males & Females & Males & Females & & Males & Females & \\
\hline Never smoker & 6 & 15 & 115 & 330 & 1 & 216 & 553 & 1 \\
\hline \multicolumn{9}{|l|}{ Cigar or pipe } \\
\hline smoker only & 5 & - & 7 & - & $\begin{array}{c}5.2 \\
(1.4-19.6)\end{array}$ & 7 & - & $\begin{array}{c}6.4 \\
(1.8-23.6)\end{array}$ \\
\hline \multicolumn{9}{|c|}{ Cigarette smoker (cigarettes/day) } \\
\hline$\leqslant 14$ & 44 & 14 & 86 & 48 & $\begin{array}{c}5.2 \\
(2.9-9.2)\end{array}$ & 165 & 89 & $\begin{array}{c}5.8 \\
(3.3-10.1)\end{array}$ \\
\hline $15-24$ & 69 & 4 & 98 & 21 & $\begin{array}{c}5.8 \\
(3.2-10.5)\end{array}$ & 221 & 47 & $\begin{array}{c}6.1 \\
(3.5-10.9)\end{array}$ \\
\hline$\geqslant 25$ & 48 & 1 & 40 & 8 & $\begin{array}{c}9.6 \\
(4.9-18.9)\end{array}$ & 80 & 7 & $\begin{array}{c}12.2 \\
(6.4-23.2)\end{array}$ \\
\hline$X_{1}^{2}$ trend & & & & & $42.1 \dagger$ & & & $57.5 \dagger$ \\
\hline \multicolumn{9}{|c|}{ Duration of smoking (years) } \\
\hline$<30$ & 53 & 4 & 161 & 76 & $\begin{array}{c}2.7 \\
(1.5-4.9)\end{array}$ & 391 & 146 & $\begin{array}{c}2.7 \\
(1.5-4.7)\end{array}$ \\
\hline $30-39$ & 69 & 9 & 99 & 24 & $\begin{array}{c}7.0 \\
(3.9-12.6)\end{array}$ & 221 & 37 & $\begin{array}{c}6.9 \\
(3.9-12.1)\end{array}$ \\
\hline$\geqslant 40$ & 99 & 8 & 171 & 15 & $\begin{array}{c}7.4 \\
(4.0-13.6)\end{array}$ & 266 & 22 & $\begin{array}{c}8.8 \\
(4.9-15.6)\end{array}$ \\
\hline$X_{1}^{2}$ trend & & & & & $55.3 \dagger$ & & & $75.9 \dagger$ \\
\hline \multicolumn{9}{|c|}{ Age at starting smoking (years) } \\
\hline$\geqslant 25$ & 24 & 2 & 73 & 48 & $\begin{array}{c}2.8 \\
(1.4-5.4)\end{array}$ & 123 & 69 & $\begin{array}{c}3.3 \\
(1.7-6.2)\end{array}$ \\
\hline $17-24$ & 113 & 9 & 245 & 53 & $\begin{array}{c}4.7 \\
(2.7-8.1)\end{array}$ & 500 & 83 & $\begin{array}{c}4.9 \\
(2.9-8.4)\end{array}$ \\
\hline$\leqslant 16$ & 91 & 10 & 141 & 14 & $\begin{array}{c}6.8 \\
(3.8-12.2)\end{array}$ & 279 & 52 & $\begin{array}{c}6.6 \\
(3.8-11.5)\end{array}$ \\
\hline $\mathrm{X}_{1}^{2}$ trend & & & & & $49.0 \dagger$ & & & $51.0 \dagger$ \\
\hline \multicolumn{9}{|c|}{ Years since quitting smoking } \\
\hline$\geqslant 10$ & 22 & - & 139 & 12 & $\begin{array}{c}1.4 \\
(0.6-3.1)\end{array}$ & 236 & 25 & $\begin{array}{c}1.6 \\
(0.8-3.5)\end{array}$ \\
\hline$<10$ & 41 & 2 & 94 & 26 & $\begin{array}{c}3.9 \\
(2.0-7.8)\end{array}$ & 201 & 38 & $\begin{array}{c}3.9 \\
(2.0-7.8)\end{array}$ \\
\hline $\mathrm{X}_{1}^{2}$ trend & & & & & $18.8 \dagger$ & & & $19.2 \dagger$ \\
\hline
\end{tabular}

* Total sample size varies because of missing values.

* Estimates adjusted for age, sex, years of education, occupation and number of alcoholic drinks per week.

$\dagger \mathrm{P}<0.01$

ORs of 13.7 (95\% CI: 6.9-27.2) and 15.6 (95\% CI: 8.2-29.7), respectively. Close similarities were observed for beer and spirits as well, although these alcoholic beverages were substantially less frequently used (Table 4). The same pattern of risk was obtained as regards the total alcohol intake $(\mathrm{OR}=10.6,95 \%$ CI: 5.5-20.6, and OR $=11.4,95 \%$ CI: 6.0-21.4, using cancer and non-cancer controls, respectively).

Separate analysis of the two sexes (not shown) showed similar results, thus indicating that the close similarities in ORs based on either cancer or noncancer controls apply to males or females.

\section{DISCUSSION}

Control selection is crucial in case-control studies, since the use of inappropriate controls can lead to both selection and information bias and, therefore, affect the validity of a study. ${ }^{25}$ Cancer controls are commonly utilized in studies performed in clinical settings, where establishing an internal comparison between patients with different, but generally closely related, cancer sites (e.g. cancers of the upper respiratory and digestive tract, gynaecological tumours, etc.) seen by the same physician saves both time and money. ${ }^{26}$ However, the problem is that the similarities between such cases and controls, not only as regards the anatomical site but, in most instances, the probable aetiology, result in estimation of relative risks which are biased towards the null. Other limitations of using cancer controls, which must be borne in mind, include representative- 
TABLE 4 Odds ratios for cancer of the oral cavity and pharynx according to drinking habits. Pordenone, /taly, 1985-1990

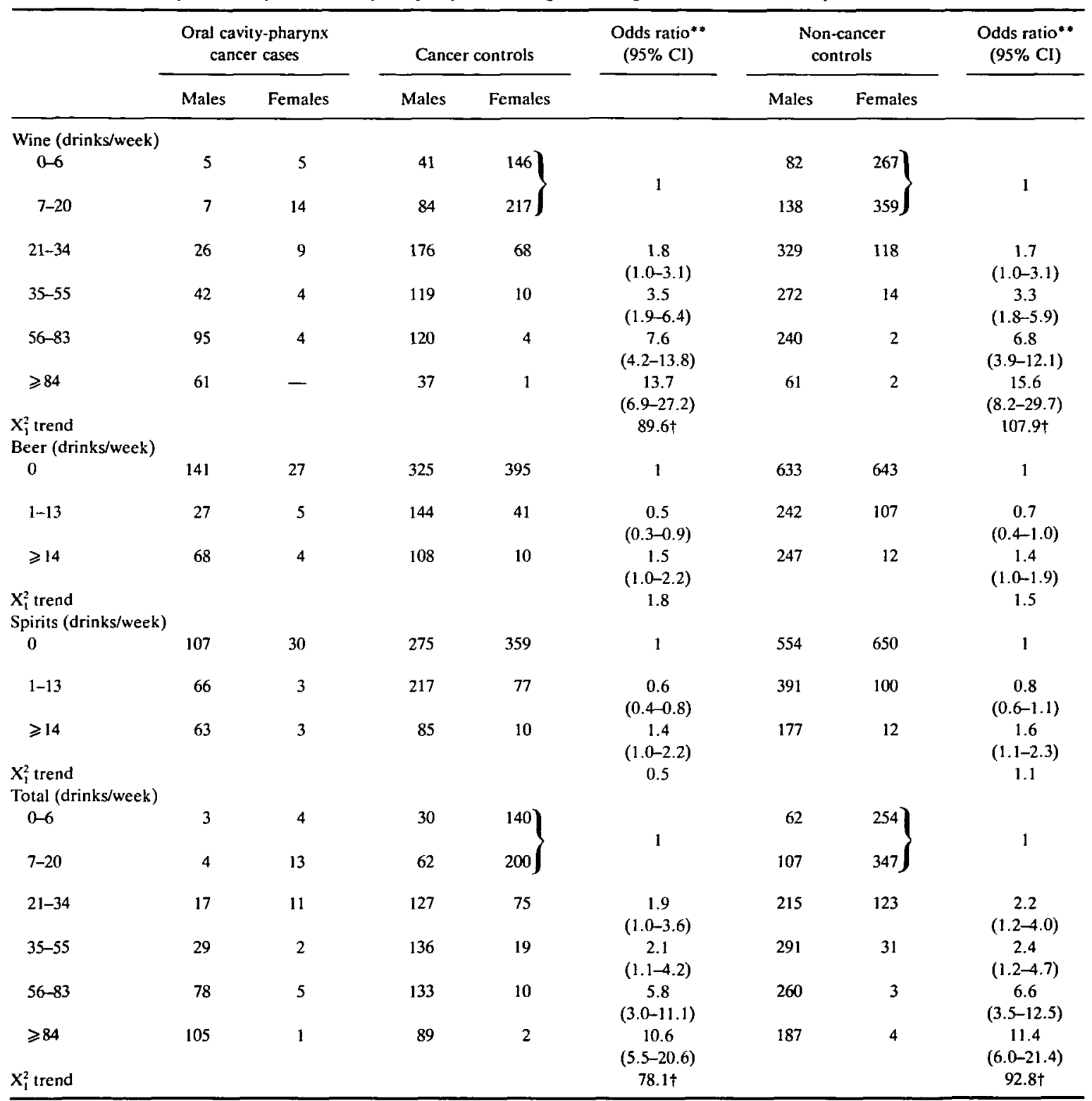

*Total sample size varies because of missing values.

**Estimates adjusted for age, sex, years of education, occupation and smoking habits.

$+\mathrm{P}<0.01$.

ness of risk estimates, additional potential confounding by exposure-related factors, and potentially different catchment areas across cancer types. ${ }^{18}$

A potential strength of the use of cancer controls, in case-control studies, is, however, the possibility of minimizing many problems related to other hospital and population controls, namely recall, selection and information bias. These biases are often not quantifiable and may be towards or away from the null. Specifically, the choice of cancer controls has been advocated in the past to reduce recall bias, since all cancer patients should have been similarly interviewed for their past medical histories and various exposures and therefore should be more apt to recall them accu- 
rately, especially in the context of their severe illness. ${ }^{17,18}$ To this extent, cancer controls can be better than non-cancer hospital controls and greatly superior to healthy community controls by providing risk estimates which are not biased away from the null value. In light of the practical difficulties in blinding the interviewer to case-control status, a reduction in interviewer bias is also likely to be achieved by using cancer patients as a control group. ${ }^{17,18}$

Generally, in cancer epidemiology, hospital and population controls have been compared. The use of other cancer sites as controls has been evaluated less often. They were first utilized as far back as 1931. ${ }^{12}$ Among case-control studies on risk factors for upper aero-digestive tract tumours, only a few studies ${ }^{12,16}$ have used other cancer patients as controls. In one of them dealing with the importance of type of alcoholic beverages on oesophageal cancer risk, Tuyns et al. ${ }^{16}$ included digestive tract cancers and other medical and surgical patients in the control group. While the analyses performed by these authors did not separate the risk estimates by cancer versus non-cancer controls, the inclusion of cancer controls were presumably done to reduce recall and interviewer bias. ${ }^{27}$

Special concern arises when the aetiologies of different types of cancer (or other diseases), even if not closely linked anatomically, are unknown and, thus, similarities in risk factors cannot be confidently discarded. ${ }^{17.18}$ In this study we attempted to minimise this problem by including control patients with cancers of different sites which, to the best of present epidemiological knowledge, are not consistently or substantially associated with tobacco and/or alcohol use. If they exist, some weak associations (e.g. direct for renal cancer ${ }^{28}$ and inverse for colorectal cancer ${ }^{29}$ ) may counterbalance each other. Similarly, nearly a fifth of noncancer controls came from each different category of disease, thus reducing the magnitude of selection bias. The effectiveness of this strategy is still open to debate, ${ }^{30-33}$ particularly in situations where exposuredisease associations may be population-specific. ${ }^{33}$ However, tobacco and alcohol have been shown to be strong and consistent risk factors for oral cavity and pharynx cancer in a large variety of populations and settings. ${ }^{7-9,34,35}$ Their specificity would not then be expected to bias the results in this study.

With regard to the specific exposures investigated in the present study, the work of Kelly et al. ${ }^{19}$ suggests that the reliability of reporting alcohol consumption, and to a lesser extent tobacco use is only moderate in a hospital interview setting, thereby calling into question the validity of such self-reports. Differential misclassification of specific risk factors across diagnostic categories was not addressed in their study, but is ultimately of concern in the present study where both the cancer controls and the hospital controls are made up of several diagnostic groups. Given that the expected biases resulting from using cancer versus non-cancer controls are in opposite directions, the congruence between the risk estimates based on cancer controls and non-cancer controls in the present study suggests that the misclassification of alcohol and tobacco consumption was, in effect, non-differential.

Finally, when hospital records constitute the predominant source of identification of cancer cases, a good comparability of catchment areas of cases with malignant diseases and controls with less severe acute conditions is very difficult to achieve. While this type of selection bias is unlikely to operate in the present study area, because of the established primary care and referral network, it is also likely to be alleviated by the choice of cancer controls. ${ }^{17,18}$

In this study the use of population controls would have been best in methodological terms, although the similarity of ORs when either cancer or non-cancer controls were used was so close as to provide, by itself, important information, particularly since all eligible and available cancer and non-cancer controls were included in the analysis. In practical terms, the present findings of high comparability of cancer and noncancer controls in the study of tobacco- and alcoholrelated tumours are useful given that, along with the minimization of selection, recall and information bias, the choice of cancer controls would diminish the costs and the difficulty of the study, and thus make it possible to increase its statistical power.

The use of other cancer types as controls may be also useful when investigating whether a specific exposure is associated with one specific tumour or to all tumours in general; or when a specific exposure, which has received particular attention in the media for its (adverse) effects, could result in overestimation because of recall bias. This could occur particularly in cancer studies on the effect of various components of diet which are subject to continuous attention in the media. Thus, while the present results strictly apply only to the effect of smoking and drinking on the risk of cancer of the oral cavity and pharynx, and are largely reassuring, they point to the need for further research on the validity of risk estimates obtaining using selected groups of hospital and non-hospital controls.

\section{ACKNOWLEDGEMENTS}

The contribution of the Italian Association for Cancer Research, Milan and the Italian National Research Council (CNR Applied Projects 'Oncology', Contract 
87.01544.44 and 'Risk Factors for Disease') are gratefully acknowledged. We also thank Mrs Tiziana Angelin, and Dr Derna Gerdol for interviewing patients and Mrs Anna Redivo and Ilaria Calderan for editorial assistance.

\section{REFERENCES}

'IARC Working Group on the Evaluation of Carcinogenic Risks to Humans. IARC Monographs on the Evaluation of carcinogenic risks to humans. Tobacco smoking. Vol 38, Lyon, International Agency for Research on Cancer, 1986.

${ }^{2}$ IARC Working Group on the Evaluation of Carcinogenic Risks to Humans. IARC Monographs on the Evaluation of carcinogenic risks to humans. Alcohol drinking. Vol. 44, Lyon, International Agency for Research on Cancer, 1988.

${ }^{3}$ Wynder E L, Bross I J, Feldman R M. A study of etiological factors in cancer of the mouth. Cancer 1957; 10: 1300-23.

${ }^{4}$ Keller A Z, Terris M. The association of alcohol and tobacco with cancer of the mouth and pharynx. Am J Public Health 1965; 55: $1578-85$.

${ }^{5}$ Doll R, Peto R. Mortality in relation to smoking: 20 years' observation on male British doctors. $\mathrm{Br}$ Med J 1976; 2: 1526-36.

${ }^{6}$ Mashberg A, Garfinkel L, Harris S. Alcohol as a primary risk factor in oral squamous carcinoma. CA 1981; 31: 146-55.

${ }^{7}$ Elwood J M, Pearson J C G, Skippen D H, Jackson S M. Alcohol, smoking, social and occupational factors in the aetiology of cancer of the oral cavity, pharynx and larynx. Int $J$ Cancer 1984; 34: 603-12.

${ }^{8}$ Blot W J, McLaughlin J K, Winn D M, et al. Smoking and drinking in relation to oral and pharyngeal cancer. Cancer Res 1988; 48: 3282-87.

${ }^{9}$ De Stefani E, Correa P, Oreggia F, et al. Black tobacco, wine and maté in oropharyngeal cancer. A case-control study from Uruguay. Rev Epidém Santé Publ 1988; 36: 389-94.

${ }^{10}$ Péquignot G, Crosignani P, Terracini B, et al. A comparative study of smoking, drinking and dietary habits in population samples in France, Italy, Spain and Switzerland. III. Consumption of alcohol. Rev Epidém Santé Publ 1988; 36: 177-85.

"Merletti F, Boffetta P, Ciccone G, Mashberg A, Terracini B. Role of tobacco and alcoholic beverages in the etiology of cancer of the oral cavity/oropharynx in Torino, Italy. Cancer Res 1989; 49: 4919-24.

${ }^{12}$ Hoffman F L. Cancer and smoking habits. Ann Surg 1931;93: 50-67.

${ }^{13}$ Schrek R, Baker L A, Ballard G P, Dolgoff S. Tobacco smoking as an etiologic factor in disease. 1. Cancer. Cancer Res 1950; 10: 49-58.

${ }^{14}$ Feldman J G, Hazan M, Nagarajan M, Kissin B. A case-control investigation of alcohol, tobacco, and diet in head and neck cancer. Prev Med 1975; 4: 444-63.

${ }^{15}$ Williams R R, Horm J W. Association of cancer sites with tobacco and alcohol consumption and socioeconomic status of patients: Interview study from the Third National Cancer Survey. J N C I 1977; 58: 525-47.

${ }^{16}$ Tuyns A J, Pequignot G, Abbatucci J S. Oesophageal cancer and alcohol consumption: importance of type of beverage. Int J Cancer 1979; 23: 443-7.

${ }^{17}$ Smith A H, Pearce N E, Callas P W. Cancer case-control studies with other cancer as controls. Int J Epidemiol 1988; 17: 298-306.

${ }^{18}$ Linet M S, Brookmeyer R. Use of cancer controls in case-control cancer studies. Am J Epidemiol 1987; 125: 1-11.

${ }^{19}$ Kelly J P, Rosemberg L, Kaufman D W, Shapiro S. Reliability of personal interview data in a hospital-based case-control study. Am J Epidemiol 1990; 131: 79-90.

${ }^{20}$ Franceschi S, Talamini R, Barra S, et al. Smoking and drinking in relation to cancers of the oral cavity, pharynx, larynx, and esophagus in northern Italy. Cancer Res 1990; 50: 6502-7.

${ }^{21}$ Franceschi S, Serraino D, Bidoli E, et,al. The epidemiology of nonHodgkin's lymphoma in the north-east of Italy: a hospitalbased case-control study. Leuk Res 1989; 13; 465-72.

${ }^{22}$ Franceschi S, Fassina A, Talamini R, et al. Risk factors for thyroid cancer in the northem part of Italy. Int J Epidemiol 1989; 18: 578-84.

23 Talamini R, Baròn A E, Barra S, et al. A case-control study of risk factors for renal cell cancer in northern Italy. Cancer Causes and Control 1990; 1: 125-31.

${ }^{24}$ Mauritsen R. EGRET Software Program. Seattle, WA. Statistics and Epidemiology Research Corporation. 1986.

${ }^{25}$ Schlesselman J J. Case-control Studies-Design, Conduct, Analysis. New York: Oxford University Press, 1982.

${ }^{26}$ Brugere J, Guenel P, Leclerc A, Rodriguez J. Differential effects of tobacco and alcohol in cancer of the larynx, pharynx and mouth. Cancer 1986; 57: 391-5.

${ }^{27}$ Jensen O M, Tuyns A J, Péquignot G. Usefulness of population controls in retrospective studies of alcohol consumption. I Stud Alcohol 1978; 39: 175-82.

${ }^{28}$ La Vecchia C, Negri E, D'Avanzo B, Franceschi S. Smoking and renal cell carcinoma. Cancer Res 1990; 50: 5231-3.

${ }^{29}$ Sandler R S, Sandler D P, Comstock G W, Helsing D J, Shore D L. Cigarette smoking and the risk of colorectal cancer in women. J N C I 1988; 80: 1329-33.

${ }^{30}$ Lubin J H, Hartge P. Excluding controls: Misapplication in casecontrol studies. Am J Epidemiol 1984; 120: 791-3.

${ }^{31}$ Pearce N, Checkoway $\mathrm{H}$. Case-control studies using other diseases as controls: problems of excluding exposure-related diseases. Am J Epidemiol 1988; 127: 851-56.

${ }^{32}$ Wacholder S, Silverman D T. Re: 'Case-control studies using other diseases as controls: problems of excluding exposure-related diseases'. Am J Epidemiol 1990; 132: 1017-8.

33 Pearce N, Checkoway H. The Author's Reply. Am J Epidemiol 1990; 132: 1018-9.

${ }^{34}$ Brugere J, Guenel P, Leclerc A, Rodriguez J. Differential effects of tobacco and alcohol in cancer of the larynx, pharynx, and mouth. Cancer 1986; 57: 391-5.

3s Franco E L, Kowalski L P, Oliveira B V, et al. Risk factors for oral cancer in Brazil: a case-control study. Int $J$ Cancer 1989; 43: 992-1000

(Revised version received February 199J) 